\title{
EGGSHELL REMOVAL BY LAUGHING GULLS
}

\author{
By William A. Montevecchi
}

After hatching of their young many birds either eat eggshells or remove them from the nest. This and other nest sanitation behavior, such as defecation flights from the nest and the ingestion or disposal of nestling excrement, are found among a variety of birds (Blair and Tucker, 1941; Nethersole-Thompson and Nethersole-Thompson, 1942). With some exceptions, e.g., Kittiwakes (Rissa tridactyla; Cullen, 1957), Sandwich Terns (Sterna sandvicensis; Cullen, 1960; Croze, 1970), Royal Terns (S. m. maxima; Buckley and Buckley, 1972), most Laridae tend to remove eggshells from their nests. Tinbergen et al. (1962) concluded that in Black-headed Gulls (Larus ridibundus) eggshell disposal represents a behavioral component of camouflage, i.e., removing conspicuous objects (white shell membranes) that might attract avian predators to the nest. The present experiment investigated the responsiveness of Laughing Gulls (Larus atricilla) over the course of a nesting cycle to an eggshell on the nest rim.

\section{METHODS}

Normative patterns of the eggshell removal tendencies of Laughing Gulls were obtained during 1972 and 1973 by making daily visits to 125 nests around hatching. Records were kept of whether eggshells were (a) in the nest cup, (b) within $2 \mathrm{~m}$ of the nest cup, (c) from 2 to $4 \mathrm{~m}$ from the nest cup, or (d) missing. Since most eggs were marked with ink and since eggs in neighboring nests generally hatched at different times, the shells from particular nests could usually (in about $80 \%$ of the cases) be identified. Nest checks were made daily; therefore, eggshells could have been situated where they were found from a few minutes up to about 24 hours. Shells were collected.

Eggshell tests involved placing on the nest rim the pointed end of a shell from which a chick had hatched, then recording responses to the shell for $1 \mathrm{hr}$ following a bird's return to the nest. During 1971, 1972, and 1973, 43 pairs (nests) were tested at various points in the nesting cycle from early incubation through nest evacuation. It was impossible to test the gulls during the prelaying and laying period because (a) Laughing Gulls do not build nests before egg laying, and (b) the erection of hides in the colony during these times can disrupt breeding activities. Some nests were tested repeatedly through the season, whereas others were tested only once or twice. All observations were made from hides near the nests at Brigantine Wildlife Refuge, N. J.

\section{RESULTS AND DISCUSSION}

Most Laughing Gulls remove eggshells from their nests at hatching, and they do so in various ways. During nest checks made just after hatching, only $16(6 \%)$ of 293 shells were found in the 
nest cup. Of the eggshells in the nest cup many belonged to newly hatched chicks and would probably have been removed eventually. One hundred forty-five $(50 \%)$ of the shells were found out of the nest within $2 \mathrm{~m}$ of the nest rim; $87(30 \%)$ of the shells were within $25 \mathrm{~cm}$ of the nest rim. About $9 \%(25$ shells) were between 2 and $4 \mathrm{~m}$ from the rim, whereas $43 \%$ (127) wore missing (not found within $4 \mathrm{~m}$ of the nest). Of the 102 eggshell removals observed from a hide, $51 \%$ (52) involved a gull flying with the shell away from the nest. Approximately $26 \%(26)$ of the shells were picked up by gulls that walked from the nest before dropping the shell; $24 \%$ (24) of the eggshells were picked up and simply dropped over the nest rim (Fig. 1). Observations on identifiable individuals and pairs revealed that some birds repcatedly flew off with eggshells, whereas others consistently walked with or dropped shells from the nest.

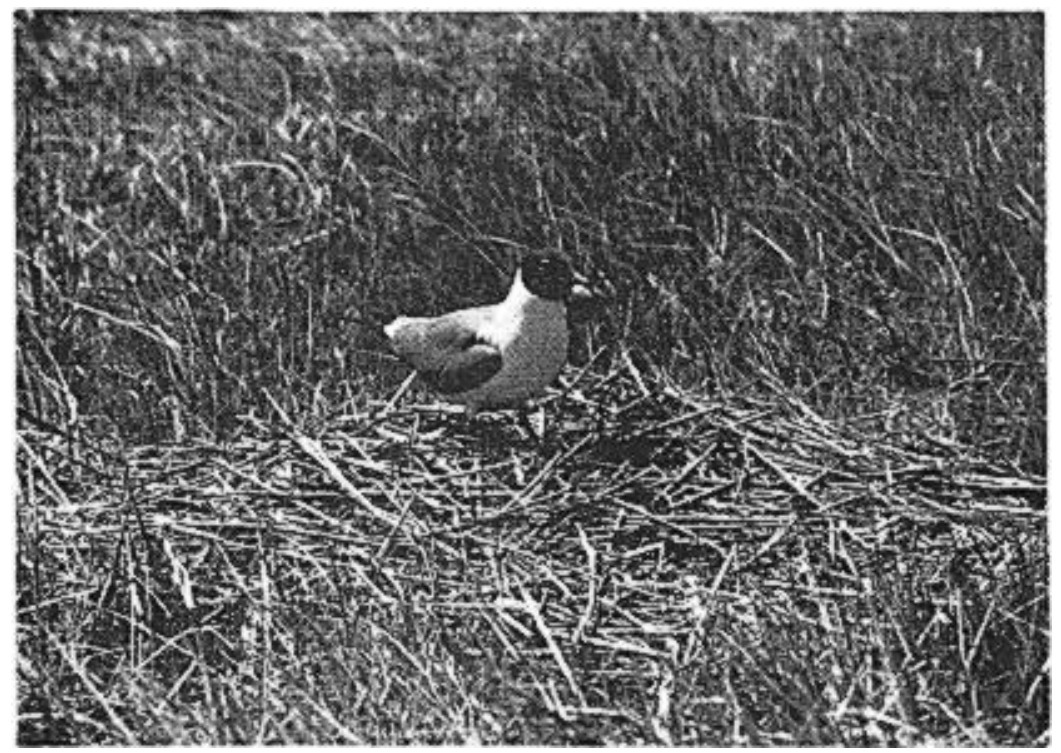

Figure 1. Laughing Gull holding an eggshell in its beak. The bird may simply drop the shell over the nest rim, walk with the shell from the nest, or fly off with the shell.

Many of the shells disposed of near the nest may have been subsequently removed farther had I not collected them. Gulls have been secn picking up and flying off with shells that lay out of the nest.

The tendency of the gulls to remove eggshells from their nests appeared strong and relatively constant during incubation but decreased sharply after hatching (Table 1). As with other incubation behavior the eggshell removal performances of Black-headed Gulls also show this trend (Beer, 1960). A few days after hatching, gull chicks venture away from the nest which may bccome a meeting 
and feeding site where young and adults interact (Beer, 1966; Evans, 1970; Miller and Emlen, 1975).

Table 1.

Mean + SE Removal Latency (min) and percentage of removals throughout the nesting cycle

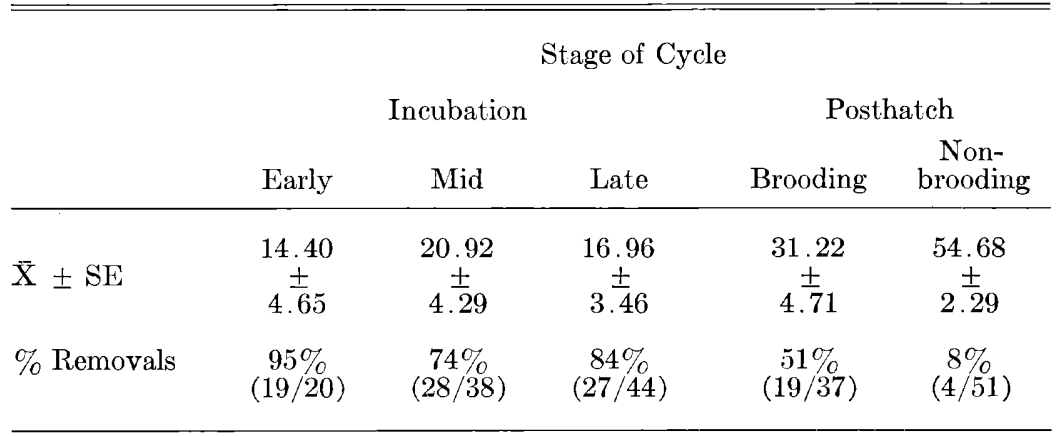

Ring Doves (Streptopelia risoria), whose altricial young remain in the nest until fledging, show an increased tendency to remove eggshells from their nests around and after hatching (Montevecchi, 1974). In comparison, birds, such as ducks, whose offspring are highly precocial (compared with semi-precocial gull chicks - Nice, 1962) may remove broken eggshells from the nest during incubation (McKinney, 1967; Johnsgard and Kear, 1968), but apparently have little inclination to do so around hatching. It is hypothesized that in general during incubation the tendency to remove eggshells from the nest (including disposal by eating) remains relatively constant and strong for most birds and that the developmental degree of young at hatching is an important determinant of a species' responsiveness at and after hatching.

Almost all Laughing Gulls that removed an eggshell during a test did so very soon after returning to the nest (Fig. 2). Approximately $75 \%$ of all removals occurred within 2 min of the time that a gull alighted on the nest. If a gull did not remove the shell during the first 10 minutes of the test, it was unlikely that it would do so during the hour. Many of the "long latency" removals that showed up in the data resulted from the quick removals of birds that relieved mates late in a test period. American Oystercatchers (Haematopus palliatus) also remove eggshells quickly (or not at all during an hour test - unpubl. data), and Ring Doves behave likewise (Montevecchi, 1974). Sabine's Gulls (Xema sabini; Brown et al. 1967), Spotted Sandpipers (Actitis malcularia); Burtt, 1972), Black-bellied Plovers (Pluvialis squatarola); Mayfield, 1973) and American Avocets (Recurvirostra americana); Gibson, 1971) remove eggshells rapidly at hatching, i.e., before chicks dry.

Tinbergen et al. (1962) contended that the relatively slow eggshell removal latency of Black-headed Gulls (in comparison with the more rapid shell removal response of European Oystercatchers (Haematopus ostralegus) and Ringed Plovers (Charadrius hiaticula) 


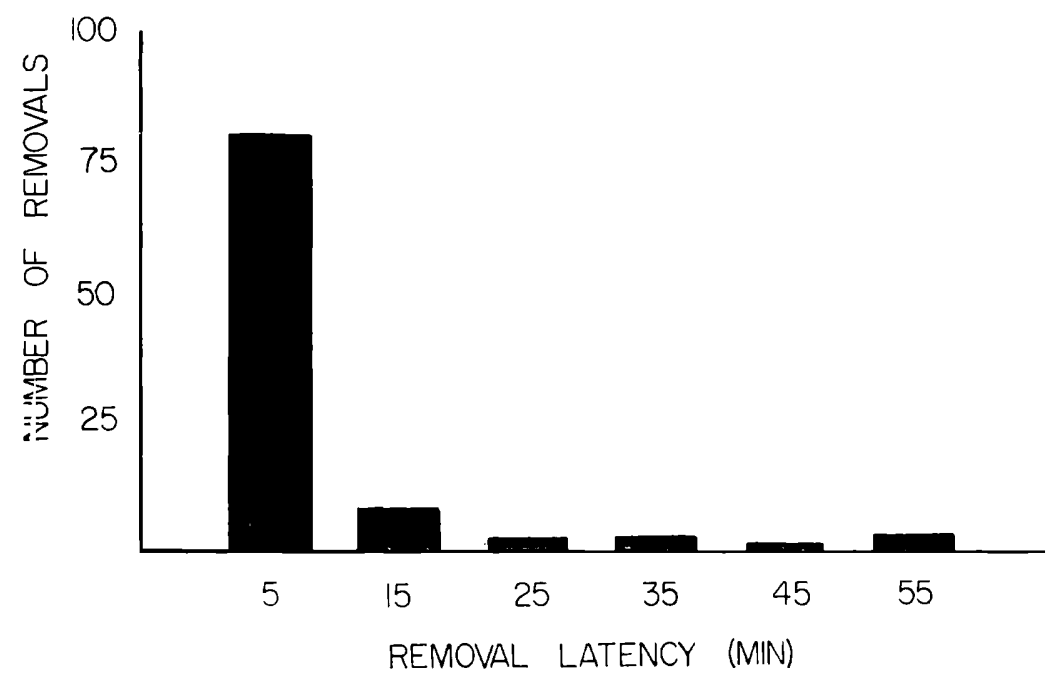

FIgURe 2. Histogram of the eggshell removal latencies of the Laughing Gulls plotted in 10-minute intervals. Combined data from tests conducted throughout the breeding cycle $(\mathrm{n}=107)$.

is adaptive. Because dry fluffy chicks are apparently less vulnerable to predators than newly hatched wet ones, a delay in removing eggshells from the nests at hatching reduces a gull's risk of losing a chick to a predator. On the basis of observations of rapid shell removal by Spotted Sandpipers, Burtt (1972) questioned the generality of this contention. Species that dispose of eggshells probably exhibit some degree of latency in doing so at hatching to insure that partially hatched young are not injured or removed. Many Laughing Gulls disposed of eggshells very close to their nests, the likely result of simply dropping a shell over the nest rim. Under these circumstances the prompt removal of eggshells at hatching would not necessitate the exposure of newly hatched wet chicks, as it might for Black-headed Gulls that apparently show a greater tendency than Laughing Gulls to $f y$ away from the nest with empty shells (M. Impekoven, pers. comm.). Furthermore, if a Laughing Gull subsequently removes a shell outside of but close to the nest, as they have been seen doing, nest site crypticity would also be maintained. In the present study as in that of Tinbergen et al. (1962), most tests were conducted at times other than at hatching; therefore, the task remains to observe and test birds with shells in the nest and at hatching in the presence of newly hatched wet chicks.

The gulls' tendency to ignore eggshells on the nest rim after the early minutes of a test may represent short term habituation to a novel stimulus (Hinde, 1970). During egg retrieval tests Blackheaded Gulls (Beer, 1962) and Herring Gulls (Larus argentatus; Baerends et al., 1970) made most of their responses to an egg outside the nest during the initial minutes of tests. 
Eggshell removal must at least for some species serve functions other than the maintenance of nest crypticity. Hole nesting species and other species with "conspicuous" eggs that dispose of eggshells are cases in point (Montevecchi, 1974). Shell disposal could aid in the prevention of nestling injury, bacterial development in the nest, the encapsulation of unhatched eggs by empty shells, and so on. Laughing Gulls lay species-typical clutches of three eggs in which first-laid eggs are significantly larger than second-laid eggs which are in turn significantly larger than third-laid eggs (Preston and Preston, 1953; Montevecchi, 1975). Among other gulls and terns that produce three-egg clutches, third eggs are consistently smaller than either first or second eggs (e.g., Fordham, 1963; Keith, 1966; Haycock and Threlfall, 1975; Nisbet and Cohen, 1975; references reviewed in Montevecchi, 1976). Third eggs usually hatch later than either of the earlier laid eggs (unpubl. data) and as a result may be encapsulated in the unremoved shells of first and second eggs. The longer an eggshell remains in the nest (possibly being incubated and shifted), the greater the possibility an unhatched egg or a chick might become entrapped in the shell. The encapsulation and subsequent hatching failure of smaller unhatched eggs has been observed among Laughing Gulls, Southern Black-backed Gulls (Larus dominicanus; Fordham, 1963), Common Terns (Sterna hirundo); Hatch, 1973), Ring Doves (Montevecchi, 1974) and Tree Swallows (E. H. Burtt, Jr., pers. comm.). The deceased incubation behavior after the hatching of the first and second eggs (Beer, 1966) may put third eggs at a hatching disadvantage (Haycock and Threlfall, 1975; but cf. Nisbet, 1974). The potential encapsulation of third eggs by unremoved shells would greatly intensify such disadvantages and has probably functioned as an important selective factor favoring the evolution of eggshell removal behavior among many gull species.

\section{SUMMARY}

Laughing Gulls remove eggshells from their nests at hatching. Flying from the nest was the most common method of disposal, although gulls also walked from the nest with shells, dropped them over the nest rim, or used a combination of methods. The gulls' tendency to remove shells was strong through incubation, but decreased sharply at hatching. On the basis of these findings and other comparative data, it is hypothesized that species disposing of eggshells and producing altricial young will show a strong tendency to do so during incubation, at and after hatching, whereas species whose young are semi-precocial and precocial will show a strong disposal response during incubation, but this responsiveness will be markedly reduced at and after hatching. Gulls habituated quickly to eggshells on the nest rim; if a gull did not remove a shell during the first $10 \mathrm{~min}$ of a test, it was unlikely to do so during an hour. The encapsulation of unhatched eggs by eggshells is an important selective factor that favors eggshell disposal. 


\section{ACKNOWLEDGMENTS}

Professors Colin G. Beer, Joanna Burger, Mei-Fang Cheng, Ernst W. Hanse, Monica Impekoven, Robert E. Ricklefs, and Jay S. Rosenblatt commented on an earlier version of this paper which was submitted as part of a larger work in partial fulfillment of requirements for the $\mathrm{Ph}$.D. degree. Research was supported by a U.S.P.H.S. Predoctoral Traineeship (MH-08604, Professors Daniel S. Lehrman and Jay S. Rosenblatt, sponsors) and U.S.P. H.S. Grant MH-16727 awarded to Professor Colin G. Beer. This is Publication No. 228 from the Institute of Animal Behavior, Rutgers University.

\section{LITERATURE CITED}

Baerends, G. P., R. H. Drent, P. Glas, and H. Groenewald. 1970. An ethological analysis of incubation behavior in the Herring Gull. In The Herring Gull and Its Egg, G. P. Baerends and R. H. Drent eds., Behaviour Suppl., 13: 135-236.

Beer, C. G. 1960. Incubation and nest-building by the Black-headed Gull. Ph.D. Thesis, Oxford University.

- 1962. The egg-rolling of Black-headed Gulls (Larus ridibundus). Ibis, 104: $388-398$.

- 1966. Incubation and nest-building behaviour of Black-headed Gulls V: The post-hatching period. Behaviour, 26: 189-214.

Blair, R. H., and B. W. Tucker. 1941. Nest sanitation. Brit. Birds, 34: 206$215,226-235,250-255$.

Brown, R. G. B., N. G. Blurton Jones and D. J. T. Hussell. 1967. The breeding behaviour of Sabine's Gull, Xema sabini. Behaviour, 28: 110-140.

Buckley, F. G. ANd P. Buckley, 1972. The breeding ecology of Royal Terns Sterna (Thalasseus) maxima maxima. Ibis, 114: 344-359.

Burta, E. H., JR. 1972. Eggshell removal in the Spotted Sandpiper. Wilson Bull., 84: 492 .

Croze, H. 1970. Searching image in Carrion Crows. Z. Tierpsychol. Suppl., 5: $1-86$.

Cullen, E. 1957. Adaptations in the Kittiwake to cliff nesting. Ibis, 99: 275-302.

Cullen, J. M. 1960. Some adaptations in the nesting behaviour of terns. Proc. Intern. Ornithol. Congr. (1958), 12: 153-157.

Evans, R. M. 1970. Imprinting and mobility in young Ring-billed Gulls, Larus delawarensis. Anim. Behav. Monogr., 3: 193-248.

Fordham, R. A. 1963. Individual and social behaviour of the Southern Blackbacked Gull. Notornis, 10: 206-222, 229-232.

Gibson, F. 1971. The breeding biology of the American Avocet (Recurvirostra americana) in Central Oregon. Condor, 73: 444-454.

НАтch, D. R. M. 1973. Hatched egg-shells covering Common Tern eggs. Blue Jay, (June): 91.

Haycock, K. A., and W. Threlfall. 1975. The breeding biology of the Herring Gull in Newfoundland. $A u k, 92: 678-697$.

Hinde, R. A. 1970. Animal Behaviour. New York, McGraw-Hill.

Johnsgard, P. A., AND J. KEar. 1968. A review of parental carrying of young by waterfowl. Living Bird, 7: 89-102.

$\mathrm{K}_{\mathrm{EITH}}$ J. A. 1966. Reproduction in a population of Herring Gulls (Larus argentatus) contaminated by DDT. J. Appl. Ecol., 3: 57-70.

Mayfield, H. F. 1973. Black-bellied Plover incubation and hatching. Wilson Bull., 85: 82-85. 
McKinney, F. 1967. Breeding behaviour of captive Shovelers. Wildfowl Trust 18th Ann. Rep.: 108-121.

Mrller, D. E., and J. T. Emlen, JR. 1975. Individual chick recognition and family integrity in the Ring-billed Gull. Behaviour, 52: 124-144.

Montevecchi, W. A. 1974. Eggshell removal and nest sanitation in Ring Doves. Wilson Bull., 86: 136-143.

—— 1975. Behavioral and ecological factors influencing the reproductive success of a tidal salt marsh colony of Laughing Gulls Larus atricilla. Ph.D. Dissertation, Rutgers University.

— 1976. Egg size and the egg predatory behavior of crows. Behaviour, in press.

Nethersole-Thompson, C., and D. Nethersole-Thompson. 1942. Eggshell disposal by birds. Brit. Birds, 35: 162-169, 190-200, 214-224, 241-250.

Nice, M. M. 1962. Development of behavior in precocial birds. Trans. Linnaean Soc. N.Y., 8: 1-211.

Nisbet, I. C. T. 1974. Further observations of terns' eggs enclosed by hatched shells. Blue Jay, 32: 164-165.

Nisbet, I. C. T., ANd M. E. Cohen. 1975. Asynchronous hatching in Common and Roseate Terns, Sterna hirundo and S. dougallii. Ibis, 117: 374-379

Preston, F. W., and E. J. Preston. 1953. Variation in the shapes of birds' eggs within the clutch. Ann. Carnegie Mus,, 33: 129-139.

Tingergen, N., G. J. Broekhuysen, F. Feekes, J. C. W. Houghton, H. Kruuk, AND E. Szulc. 1962. Egg shell removal by the Black-headed Gull, Larus ridibundus L.; a behaviour component of camouflage. Behaviour, 19: 74-117.

Institute of Animal Behavior, Rutgers University, Newark, New Jersey. Present Address: Animal Behavior Group, Department of Psychology, Memorial University, St. John's Newfoundland, A1C 5S\%, Canada. Received 23 November 1975, accepted 5 February 1976. 